\title{
Topografia, corpografia: natureza, arte e técnica na poesia de Josely Vianna Baptista
}

Resumo: Esse trabalho se propõe a analisar "Na tela rútila das pálpebras”, uma produção digital em que Josely Vianna Baptista articula palavra e voz poéticas a imagens visuais de diferentes tipos, registros e origens, associadas, por sua vez, a pesquisas históricas, geográficas e geológicas. Nesse seu trabalho procuramos apontar um caráter simultaneamente corpográfico e topográfico, na medida em que a relação entre subjetividade e espaço é tramada por um modo de olhar que se constitui como gesto sensitivo e memorioso, atravessado por alteridades, fazendo da poesia uma voz singular na medida mesmo em que imprópria.

Palavras-chave: poesia, corpografia, topografia

Abstract: This paper analyzes Josely Vianna Baptista's "Na tela rútila das pálpebras", a digital work associating poetic word and voice with visual images of different kinds, registers, and origins, which in turn are related to historical, geographic, and geological research. The work's dual character - corpographical and topographical - is pointed out, the relation between subjectivity and space being defined by away of looking involving both sensitivity and memory, marked by alterities, making poetry a singular voice, a singularity deriving from its own improper nature.

Keywords: poetry, corpography, topography

Na Tela Rútila das Pálpebras é um projeto multimídia desenvolvido por Josely Vianna Baptista - com uma equipe que envolvia um fotógrafo, um videomaker, um tradutor, um desenhista, um geógrafo, um arqueólogo, dois historiadores -, durante 2015 e 2016, e publicado como produção digital nesse último ano. Dessa produção, deve-se dizer desde logo que, a despeito de suas singularidades, radicaliza características presentes em todo o trabalho de escrita de Josely. Com essa designação - escrita - pretendemos nele enfatizar a articulação de uma rede de atividades e linguagens não só simultâneas mas suplementares - como poeta, tradutora, artista visual, pesquisadora da cultura de povos ameríndios, organizadora de coletâneas poéticas.

Em todas elas, a tensão entre palavra e imagem é motivação fundamental de um movimento através do qual o poético parece definir-se, conforme queria Jean-Luc Nancy, como "renúncia persistente em deixar a poesia identificar-se com qualquer gênero 
ou modo" (Nancy 2005: 13). Esse esforço de desidentificação implica um valor estético e político intrinsecamente ligado ao de associação do poético a uma voz imprópria - noção emprestada da crítica argentina Ana Porrúa para definir aquela voz cuja "propiedad, en este caso, es la desapropiación del yo poético hablando en el círculo seguro del poema y la reapropiación de lo que suena por afuera de ese círculo" (Porrua 2016: 248). A impropriedade, desse modo, diz respeito tanto a uma potência de desestabilização da forma quanto à convivência nela de diferentes forças de subjetivação.

Assim já ocorre com suas primeiras publicações, os livros de poemas A R e Corpografia, de 1991 e 1992, ${ }^{1}$ respectivamente, marcados pelo procedimento por ela chamado de aeração de palavras e versos, que atualiza o "labirinto cúbico" barroco para compor uma "estrofação sensível”, na qual "a dispersão das letras quer desautomatizar o olhar e trazer o fôlego do leitor ao centro mesmo do poema" (Baptista 2016). Tal dispersão se inscreve em blocos cerrados de texto, configurados pelo que poderíamos chamar de enjambements prosaicizantes, que imprimem nos versos isomórficos o caráter de linha e hibridizam o semântico e o semiótico, conforme considera Henri Meschonic (1982). Nesse jogo entre ampliação horizontalizante e contenção vertical se abre também espaço para a inscrição labiríntica e citacional de obras e autores outros. E tal inscrição vai reafirmar o poema/bloco/corpográfico - tecido de voz, respiração, visão - em sua porosidade, como passagem para além de seus próprios limites, mostrando que estes devem ser antes pensados como confins, limiares. Na visão de Massimo Cacciari, que permite desenvolver a noção benjaminiana de passagem,

confim se pode dizer de muitas maneiras. Em geral, o termo parece indicar a "linha" ao longo da qual dois domínios se tocam: cum-finis. Dessa forma, o confim distingue, tornando comum; estabelece uma distinção determinando uma ad-finitas. fixado o finis (e em finis ressoa provavelmente a mesma raiz de figere), "inexoravelmente" se determina um "contato". (Cacciari 2000: 73)

No livro Corpografia, cujo subtítulo é justo “Autópsia poética das passagens”, podemos ver/ler um corpo/poema, ao mesmo tempo fixado e móvel, nomeado como "Colosso impenetrável", ${ }^{3}$ e acompanhado, como os demais, de desenho em grafite de Francisco Faria - parceiro constante dos trabalhos de Josely - em que diferentes tons de cinza compõem uma imagem na qual mar, pedra, ondas-dobras se confundem porosamente:

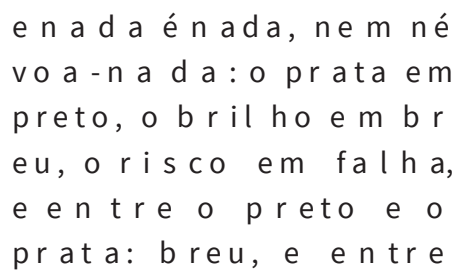




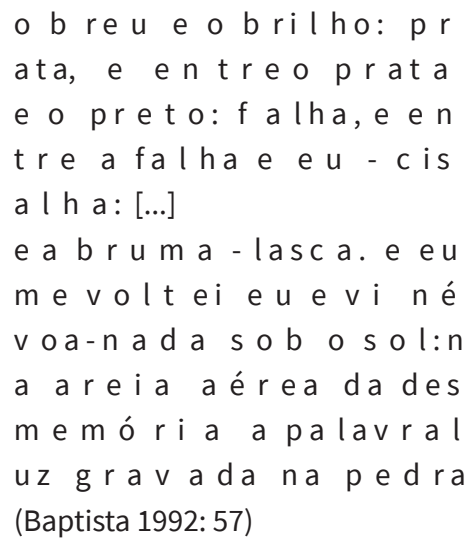

E se escolhemos tal passagem do poema, no duplo sentido desse termo portanto, é porque nela o espaçamento gráfico e citacional se faz aí junto com a solicitação, marcada em itálico, do gesto tradutório e transcriador de Haroldo de Campos, dirigido a um discurso cosmogônico da tradição ocidental, o Eclesiastes (Campos 1990). Mistura de escritas, de vozes e de temporalidades, essa passagem mesma pode ser então considerada uma cosmo-gonia que se desdobra em genealogia, associando o poético, o mítico, o histórico em torno e a partir da construção difrásica névoa-nada.

Essa relação continua a sustentar a última publicação de Josely Vianna Baptista, onde nos deparamos de novo e sintomaticamente com uma tradução, de novo a tradução de um discurso cosmogônico, dessa vez ameríndio, o Popol Vuh do povo quiché-maia (Baptista 2019). Neste texto, aliás, ela vai considerar justo o difrasismo um procedimento fundamental, assim como o da dispersão de repetições e paralelismos poéticos em um rio de prosa. ${ }^{4} \mathrm{E}$ vai caracterizar ainda o mais recente e com certeza mais repercutido livro de poemas de Josely, Roça Barroca, cuja escrita se tece também no cruzamento de imaginação, tradução e citação. No título da seção dedicada a poemas de sua autoria, a imagem "moradas nômades" contribui para relativizar a ideia mesma de autoria, assim como as de pertencimento e enraizamento, abaladas já pela convivência dos poemas nesse livro com traduções de mitos guaranis, um elucidário dos termos desses mitos, uma leitura interpretativa e histórica da cultura guarani, intitulada "Em busca do tempo dos longos sóis eternos", e as "Notas sobre um percurso compartilhado", escritas por Francisco Faria. Essa imagem e essa organização do livro atualizam mais uma vez o valor de confim/porosidade/passagem, como ocorre também já com a imagem cronotópica da "roça barroca". Em ambas se fundem cultivo e percurso, enraizamento e deslocamento, natureza e cultura, por diferentes espaços e tempos, associando o mito guarani da busca nômade da terra sem mal à promessa política de um mundo ainda por vir e concretizando mais uma vez, desse modo, uma poética imprópria. Como considera o pesquisador americano Malcom Mcnee: 
Conceptually, it gives voice to the increasingly urgent search for and cultivation of cosmovisions by which to imagine responses to environmental crisis and degradation at both local and planetary scales. Her engagement with the Mbyá cosmogonic songs positions them as part of a counter conquest poet-ics, not only in the sense of a poetics of resistance to the colonial conquest of peoples and territory, but also as a cosmovision that is counter to that of conquest and control that has largely figured as the conception of nature in modernity (2014: 97)

Da experiência de tradução do Popol Vuh, comparável nesse sentido a todas as escritas aqui citadas anteriormente, Josely, retomando e desdobrando o paradigma espaço-temporal da terra e de seu cultivo-percurso, diz ter sido um esforço labiríntico, interminável, uma obsessão poético-interpretativa para reconfigurar uma topografia, para a qual "percorreu variada cartografia de estudos, códices e dicionários" (idem). Podemos associar então a escrita poética e a tradutória, em sua condição de passagem e inacabamento, a um mesmo gesto que, encenando uma força operacional dos começos ${ }^{5}$ - e de novo remetendo a Haroldo de Campos e sua galáxia neobarroca - faz com que o originário continue a viver, em pervivência, conforme a tradução desse poeta para o termo alemão Fortleben, com que Walter Benjamin define justamente o efeito da tarefa do tradutor (Campos 1969). ${ }^{6}$

Não seria então de todo gratuito lembrar aqui a primeira tradução publicada por Josely, em 1985, a do romance Os Passos Perdidos, do escritor cubano Alejo Carpentier, que nele narra o contraste entre cultura ocidental e ameríndia, através das aventuras de um músico europeu que vem pesquisar na selva amazônica instrumentos musicais originários. Se esse percurso produz perdas e desconsolos, se abre também a potencialidades indeterminadas e intermináveis, das quais é testemunha a própria escrita do romance, o modo como termina, deixando em suspenso o fim do percurso, sua tradução, os desdobramentos dessa tradução nos futuros trabalhos de Josely e o modo como neles o confronto com a dife-rença, a perda e a ruína se transforma em gesto de aceno insistente para o outro, para o outro de si mesmo.

E é bastante sugestivo perceber mais desdobramentos desse potencial no trabalho de outro escritor que, como Josely, investe nas relações entre cosmogonia e genealogia, entre cultura ocidental e cultura ameríndia, Sérgio Medeiros. Pois ele também traduz o Popol Vuh - e como uma das introduções a essa publicação inscreve, em instigante coincidência, ensaio onde reflete sobre o significado da experiência dessa vez real do músico "futurista" francês Edgar Varèse. Este, em 1915, redescobre, a partir de uma estada em Nova York, o potencial vanguardista da percussão de povos ameríndios "primitivos", que Sérgio, citando ainda a relação entre Varèse, Villa-lobos e, não por acaso, Carpentier, vai apontar como tema posterior das reflexões de um John Cage, entre outros (Medeiros 2003). ${ }^{7}$

As imagens do cultivo e do percurso, relacionando então escrita poética e tradutória à experiência da/na terra como simultaneamente solo e soleira, nos permitem retraçar 
uma teia discursiva usada tanto para compor esses e outros textos como para defini-los objetiva, conceitual e também metaforicamente. De fato, Na Tela Rútila das Pálpebras tem como subtítulo Uma topografia dos campos gerais do Paraná. Topografia e também cartografia, usadas por ela, como se vê, recorrentemente, indicam aí essa relação entre escrita, enraizamento e deslocamento como, também, "afloramento" à superfície de diferentes camadas temporais - o texto e a terra como palimpsestos a serem continua e interminavelmente revolvidos, decifrados, traduzidos, como Josely afirma nas "Anotações" iniciais sobre seu projeto.

Na tela rútila das pálpebras então surgiu, à primeira vista, de uma vontade minha de merguIhar nessa paisagem fascinante e de raspar a pátina, a densa nuvem de névoas que eu deitara sobre a terra e a imagem da família. [...]então foi quase natural eu imaginar uma viagem por essas topografias cambiantes, por esse lugar que em sonhos me parecia um palimpsesto intraduzível - que ao ser raspado deixava à mostra ora desertos, ora mares, rastilhos de lava brutalmente aflorados, vales, breu de profundezas, moldes de pedra e uma forja de magmas. (Baptista 2016)

Cultivo e percurso, na medida em que nomeados também como cartografia e topo-grafia confirmam que essa interminável decifração se produz através da articulação verbo-visual de arte e ciência, natureza e técnica que solicita - lembrando o uso derridiano desse verbo - a noção mesma de campo. Agora, enquanto campos gerais, ela faz ressoar aí também a simultaneamente mítica, geográfica e histórica natureza do sertão de Guimarães Rosa em seu indeterminado e indeterminante "nonada" e "redemunho", desestabilizando as fronteiras epistemológicas que essa noção impõe às práticas artísticas e científicas do Ocidente. ${ }^{8}$

De fato, e agora nesses campos gerais da produção digital aqui abordada, convivem com o poema de Josely intitulado "Fábula", os poemas "Dádiva”, do cubano José Kozer e "Rio do céu", do mapuche chileno Leonel Lienlaf - ambos em sua versão original e na tradução feita por ela -, e um poema recuperado de Augusto dos Anjos, sobre "A derrubada de uma árvore", além de citações de outros vários poetas. A esses poemas se juntam um glossário histórico-geográfico, fotografias originais e reproduções de diferentes épocas, desenhos, um vídeo acompanhado de performance vocal de poemas, mapas geográficos e topográficos. E ainda o que Josely nomeia como "palimpsestos "visuais" - cujo conjunto vai chamar de "Itororó", palavra indígena que significa "rio barulhento", como essa cambiante cachoeira de vozes e imagens em que, segundo ela "fluem memória histórica e memória amorosa" (ibidem). Essas imagens são construídas pela superposição de fotogramas de paisagens, de fragmentos de fotos, cartas, memórias e poemas, que por isso podemos considerar como que sínteses miniaturizadas, emblemas móveis dessa produção, que retrabalha em campos/palimpsestos verbo-visuais o mecanismo de hiperinformação característico da internet. 
Podemos recuperar aqui então o duplo valor da noção de voz imprópria, referida anteriormente. E nela enfatizar a convivência heterogênea de linguagens, culturas, subjetividades, pontos de vista, discursos, inclusive agora os das ciências ditas "naturais" e "exatas". Decorre daí também um deslizamento ontológico das fronteiras entre o humano e o não-humano, assim como entre o técnico e o natural, fronteiras agora tornadas limiares. De um lado, a compreensão da natureza como sistema cultural revela resíduos de factualidade obstinada, impenetrável; de outro lado, as visões por ela provocadas na tela rútila das pálpebras evidenciam a arte como província que as explicações naturalistas não conseguem esgotar - como bem considera o antropólogo francês Philippe Descola (2011).

Talvez esse duplo movimento possa ser considerado a motivação e o efeito mais singulares do uso da palavra para encenar o que poderíamos chamar de fenomenologia da imagem e já apontamos acima como uma das principais características, se não a principal, do trabalho de Josely. "Como gostaria de poder ver o poder ver", nos diz outra escritora brasileira contemporânea, Julia de Carvalho Hansen (2016:13), em que essa fenomenologia aparece também associada, por outras vias, a uma recuperação mito-poética-científica da natureza a partir da qual na verdade se produz uma subjetivação despersonificada, estranhada de si mesma, como fábula invertida, a contrapelo de sua personificação romântico-moderna. E performada, nas palavras de Josely, como "um impulso de ver outros tempos dentro do meu tempo, outro(s) sentido(s) para meus sentidos, como o indício de um rosto inteiro vislumbrado nas lascas de um espelho quebrado em mil pedaços" (Baptista 2016).

Não por acaso, o poema "Fábula", produzido "na tela rútila das pálpebras", tem seu fluxo marcado por começos-recomeços estróficos sempre mobilizados por um jogo simultâneo de negação e interrogação que encena o olhar num espaço-tempo aquém de toda plenitude subjetiva ou objetiva, onírica, artística ou científica. E seu retornar sobre si mesmo, abrindo-o e também à escrita ao leitor/espectador, chamando-o para esse interior/exterior que é também o do poema e o da imagem, da pedra, do rio, do vento, para ver e aprender a poder ver na sua superfície "naturalmente visível” "pétreos afloramentos que evocam ruínas", "rios míticos de muita história confluindo", "o sol sombrio arborescendo avessos" - evidências que são também enigmas, vestígios de águas, pedras, eras anteriores.

De que lugar você fala?

Sob esse solo raso e arenoso

hibernam bulbos, sob esse charco podre se emaranham gemas de rizomas, lugares onde tudo pode ser um começo, frutos de futuros. 
Nesse sentido, e como indicava já o uso do termo guarani "Itororó", o fluxo de palavras e de imagens implica intrinsecamente a interrupção e a deriva como a de um rio com pedras, de "margens férteis de formas", que se concentra e dispersa, podendo se decupar, chover e evaporar. "Não vê o roteiro dos rios/correndo para o oeste?/O sol sombrio arborescendo avessos/no burburinho dos arroios?", "Rios e abismos não demarcam fronteiras./São caminhos./ No céu as constelações se movem como águias,/ onças pintadas, pássaros nômades/ Nada está fora do lugar./ Você vê?"

Esse movimento em que uma sintaxe do olhar se constitui como fluxo contínuo mas desestabilizado por interrogações e negações, constitui também a relação mesma entre palavra, imagem e voz - "Que língua pode abrigar um broto/em seu instante de surto/,e significá-lo? "[...] Como descrever o veludo dessa flor/- desse novelo feito de minúsculos velos/em tons de seco que é essa flor?”. E nos remete à interessante distinção apontada por Didi-Huberman no interior mesmo da palavra francesa tableaux, que significa ao mesmo tempo quadro e mesa. O primeiro seria "superficie de inscripción de una obra que se cree definitiva ante la historia", representa lo limitado, lo cerrado sobre sí mismo" (2010). Já a mesa seria, ao contrário, suporte de um trabalho que sempre se pode modificar, evidenciando o princípio da porosidade. Assim a escritora, transformando a paisagem dos campos em campo/mesa de montagem de linguagens/técnicas várias, reencena discursivamente o movimento pelo qual vê através do abrir e fechar os olhos, a pálpebra indiciando aí tanto uma maior corporeidade da visão, quanto seu caráter não contínuo, não imediato, isto é corpográfico.

É interessante aqui ressaltar mais uma vez que a produtividade dessa associação entre corpo, palavra e imagem está associada à possibilidade do cruzamento espaço-temporal de espaços, tempos e vozes. Talvez essa força voco-visual imprópria possa estar emblematizada pelo modo como Josely e suas parcerias atualizam a imagem da nuvem/ neblina/nada originária, sempre cambiante, em movimento,como diz também a propósito da presença do poema ameríndio-chileno "Rio do céu", que define como "nuvem/ voz que chove sobre a /tela/poema", que frutifica assim em não sendo mais só seu/sua:

Por acaso a palavra llaillai

guarda o murmúrio dos rios em treliça

que correm em desfiladeiros, sobre os lajedos?

(...)

Sob o Sol o rio ascende em nuvem, que descende em chuva, que mergulha na Terra (em suas grutas fundas) e depois sobe em neblina propícia para semeaduras. 
Na tela rútila das pálpebras, portanto, atualiza um trabalho individual e coletivo com visões técnicas e afetivas, em que, de olhos abertos/fechados, a imaginação se produz e se coloca, segundo uma definição de Didi-Huberman, como capaz de outorgar-nos "un conocimiento por su potencia intrínseca de montaje (consistente en descubrir - precisamente allí donde rechaza los vínculos suscitados por las semejanzas obvias - vínculos que la observación directa es incapaz de discernir" (2010).

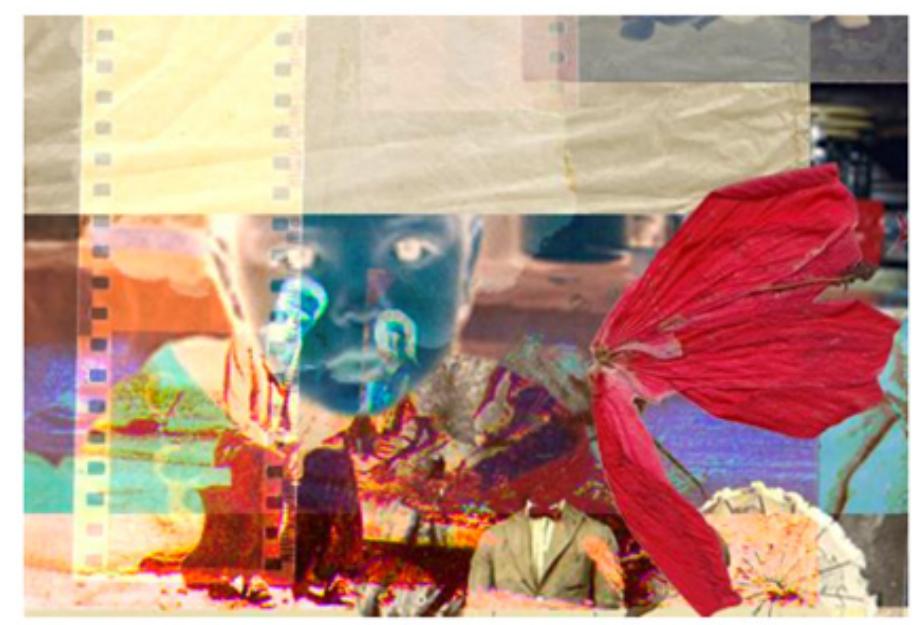

\section{FÁBULA: na tela rútila das pálpebras}

\section{Pedro Jerónimo Vaz de Faria}

Fotografia, fotogramas e quase-imagens

(palimpsestos) para poema

de Josely Vianna Baptista

Palimpsestos digitais

executados por Gui Zamaner 


\section{NOTAS}

"Celia Pedrosa é pesquisadora 1 do CNPq e professora associada de Literatura Brasileira e Literatura Comparada na Universidade Federal Fluminense, onde coordena os Grupos de Pesquisa Poesia e contemporaneidade e Pensamento teórico-crítico do contemporâneo. Coordenou convênio CAPES-FCT entre a UFF e a Universidade do Porto e atualmente entre a UFF e a Universidade Tees de Febrero (Buenos Aires), integrando ainda equipe de convênio com a Universidade Nova de Lisboa. Tem publicados os livros Antonio Candido: a palavra empenhada (EdUSP/EdUFF) e Ensaios sobre poesia e contemporaneidade, além de, como organizadora, cinco coletâneas de ensaios sobre poesia e crítica contemporâneas.

${ }^{1}$ Esses livros foram reunidos em Sol sobre Nuvens, publicação de 2007 que inclui também as seções "Os poros flóridos", "Poemas esparsos" e "Apêndice I" (da edição original de Corpografia) e "Apêndice II” (da edição original de Os poros flóridos.

${ }^{2}$ Imagem comumente usada por Josely, ela dá nome inclusive a um livro e a um poema seus, Os poros flóridos, referido na nota acima.

${ }^{3}$ Nesse título se trama um jogo citacional que optamos por não explorar e remete tanto à mitologia clássica quanto à poesia moderna de Silvia Plath que intitula "Colosso" seu primeiro livro de poemas, publicado em 1960, e ainda a uma personagem mutante de série televisiva. Mas importa ressaltar o quanto essa referência pode contribuir para entender o jogo entre monumentalização e desmonumentalização na construção verticalmente porosa desse e de outros poemas de Josely.

${ }^{4}$ Cf. sua apresentação dessa tradução, “Jogo de espelhos de obsidiana” (2019: 17-27). Obsidiana é o nome dado a um a pedra vítrea de origem vulcânica, usada na cultura maia, entre outras.

${ }^{5}$ Essa expressão foi usada na exposição sobre a obra de Haroldo de Campos, e em referência a seu livro Galáxias, realizada em São Paulo, em 2016, com curadoria de Julio Mendonça. A expressão sintetiza muito bem as teses sobre a origem não originária barroca discutidas pelo autor no ensaio “Da razão antropofágica” (1992). ${ }^{6} \mathrm{Cf}$. a propósito, Scramim, Susana: "Mais além da grande saudade, mais aquém da constatação da catástrofe" (2014: 24-33).

${ }^{7}$ Sem dúvida é importante pensar, a partir da comparação entre essas narrativas, essas traduções e sua recepção, sobre os diferentes modos de pensar a relação entre subjetividade e alteridade que na literatura latino-americana foram discutidos ao longo do século XX. E em que medida neles a relação entre literatura, mitologia e antropologia pode significar uma proposta de inscrição transcultural ou problematização de um discurso universal hegemônico, como referimos acima a respeito de Josely. Cf. a propósito, o ensaio de Marcos Natali sobre José María Arguedas, “José María Arguedas aquém da literatura” (2005).

${ }^{8}$ Cf. nas "Anotações", passagem sobre "fotogramas do sertão metafísico de Guimarães Rosa, das lonjuras existenciais dos pampas de Jorge Luis Borges, das montanhas fabulosas e dos rios andinos de José María Arguedas".

${ }^{9}$ A respeito do uso do termo emblema, cf. o texto de Osvaldo Silvestre (2017) sobre a poesia de Carlito Azevedo. Lembre-se que o emblema é procedimento verbi-visual tipicamente barroco e que já o referimos acima, embo-ra sem assim identificá-lo, quando falamos sobre o labirinto cúbico dos poemas de Josely. 


\section{BIBLIOGRAFIA}

Antelo, Raul (2008), “Lindes, limites, limiares”, in Boletim de Pesquisa do NELIC, Florianópolis, UFSC, Edição Especial Lindes.

Baptista, Josely Vianna (2019), Popol Vuh. Tradução crítica e notas, São Paulo, Ubu Editora/Fondo de Cultura Económica/Embaixada do México no Brasil.

-- (2016), Na tela rútila das pálpebras. <www.natelarutiladaspalpebras>, último acesso em out.2019.

-- (2007), Sol sobre nuvens, São Paulo: Perspectiva.

-- (1992), Corpografia, São Paulo, Iluminuras.

Cacciari, Massimo (2000), "Nome di luogo: confini”, in aut-aut, n² 299-300, Milão, 73-74.

Campos, Haroldo de (1969), "A Poética da tradução”, in A arte no Horizonte do Provável, São Paulo, Perspectiva: 93-130.

-- (1990), Qohélet / O-que-sabe - Eclesiastes, tradução e notas, São Paulo, Perspectiva.

-- (1992), “Da razão antropofágica”, in Metalinguagem e outras metas, São Paulo, Perspectiva.

Didi-Huberman, Georges (2010), “Dispar(at)es 'Leer lo nunca escrito’”, in Atlas ¿Cómo llevar el mundo a cues-tas?, Madrid, MNCERS: 14-58.

Descola, Phillipe (2011), "Más allá de la naturaleza y de la cultura”, in Cultura y Naturaleza, Bogotá, Jardín Botánico de Bogotá, José Celestino Mutis: 75-96.

Hansen, Julia de Carvalho (2016), Seiva veneno ou fruto, Belo Horizonte, Chão da Feira.

McNee, Malcolm (2014), "Sérgio Medeiros and Josely Vianna Baptista: meta-landscape and the (re)-turn of the native", in The Environmental Imaginary in Brazilian Poetry and Art, Pallgrave McMillan: 71-99.

Medeiros, Sérgio (2003), "O Popol vuh eletrônico: mito e vanguarda”, in Wataguin, Lucia, Brasil e Itália: Vanguardas, São Paulo, Ateliê: 90-100.

Meschonnic, Henri (1982), Critique du rythme: antropologie historique du language, Paris, Verdier.

Nancy, Jean-Luc (2005), Resistência da poesia, São Paulo, Vendaval.

Natali, Marcos (2005), “José Maria Arguedas aquém da literatura”, in Revista de Estudos Avançados, $\mathrm{n}^{\circ}$ 55, Dossiê América Latina, São Paulo, USP.

Porrua, Ana (2016), "La voz impropia: poesía e política”, in Revista Crítica Cultural, v.11, $\mathrm{n}^{\circ} 2$, Florianópolis, UFSC: 241-249.

Rancière, Jacques (1996), O Desentendimento: Política e Filosofia, São Paulo, Editora 34.

Scramim, Susana (2014), "Para além da grande saudade, para aquém da constatação da catástrofe", in Sobrevivência e devir da leitura, Belo Horizonte.

Silvestre, Osvaldo (2017), "A poesia e a condição pós-média: o caso de Monodrama, de Carlito Azevedo", in Revista Texto Poético, v.19, n²3, ANPOLL. 